University of South Florida

DIGITAL COMMONS

Digital Commons @ University of

@ UNIVERSITY OF SOUTH FLORIDA

South Florida

1990

\title{
Interannual Differences of Geosat Altimeter Heights and Sea Level: The Importance of a Datum
}

Klaus Wyrtki

Gary Mitchum

University of Hawaii, mitchum@usf.edu

Follow this and additional works at: https://digitalcommons.usf.edu/msc_facpub

Part of the Life Sciences Commons

\section{Scholar Commons Citation}

Wyrtki, Klaus and Mitchum, Gary, "Interannual Differences of Geosat Altimeter Heights and Sea Level: The Importance of a Datum" (1990). Marine Science Faculty Publications. 2078.

https://digitalcommons.usf.edu/msc_facpub/2078

This Article is brought to you for free and open access by the College of Marine Science at Digital Commons @ University of South Florida. It has been accepted for inclusion in Marine Science Faculty Publications by an authorized administrator of Digital Commons @ University of South Florida. For more information, please contact digitalcommons@usf.edu. 


\title{
Interannual Differences of Geosat Altimeter Heights and Sea Level: The Importance of a Datum
}

\author{
KLAUS Wyrtki AND GaRY Mitchum \\ TOGA Sea Level Center, University of Hawaii, Honolulu
}

\begin{abstract}
Sea surface height data from the Geosat altimeter are compared with island sea level data from 18 gauges in the western and central tropical Pacific during December 1986 to November 1987. Care was taken to ensure that the two data sets are referenced to the same mean surface. This was done by requiring that both data sets have a zero mean sea level over the period April 1985 to April 1986. When the annual means are computed at each station in the later time period, we find that the annual mean sea surface height values have drifted away from the corresponding sea level values by as much as 16 $\mathrm{cm}$. Further, the pattern of differences that develop between the two data sets is not random but is spatially coherent with a strong east-west gradient. These observations illustrate the necessity for sea surface height data to be referred to a well-defined zero point, a datum, in order to reliably monitor interannual changes in the sea surface topography. Until these differences can be eliminated, it will be necessary to use tide gauge data as benchmarks for the altimeter sea surface height data.
\end{abstract}

\section{INTRODUCTION}

The sea surface is clearly defined as the boundary between ocean and atmosphere. It is the boundary between water and air, as wavy as the surface may be. The sea surface is not well defined when ice floats on the water. Where the sea surface intersects the land, sea level is defined. Sea level is traditionally measured by tide gauges, which measure the position of the sea surface near the land relative to a fixed point on land, called a benchmark or datum. Variations of sea level can be due either to vertical movements of the water or to vertical movements of the land. Therefore monthly or annual averages of sea level measurements are often called "relative sea level." Despite the uncertainty in the absolute sea level caused by vertical movements of the land, the fact that tide gauges are referenced to the datum is of primary importance. It is only this vertical reference point that allows the determination of slow, subtle changes in sea level over the course of years and decades. One reason why the height of the sea surface in the open ocean is difficult to measure is because of the lack of a reference point or a reference surface.

Several methods are available to measure variations of the height of the sea surface in the open ocean. We will use the term "sea surface height" for such measurements to distinguish them from measurements of "sea level," which is strictly defined only along the boundary of land and sea. Inverted echo sounders can measure variations of the distance from the ocean bottom to the sea surface, but the absolute elevation is rather inaccurate, and the datum on the ocean bottom is not accessible. Satellite altimeters can measure variations of the distance between the satellite and the sea surface, but these measurements are relative to the orbit of the satellite, which varies in time and at present provides an unsatisfactory datum. An indirect method is the determination of sea surface height from measurements of density in the ocean through the calculation of dynamic height relative to a deep and unknown reference surface.

Copyright 1990 by the American Geophysical Union.

Paper number 89JC03264.

0148-0227/90/89JC-03264\$05.00
The various techniques for measuring sea surface height or sea level have different strengths and weaknesses. Observations of sea level at individual locations give continuous records. However, in the open ocean the locations are few and limited to the available islands, where gauges are usually located inside harbors or lagoons. Computations of dynamic height are relatively few, and obtaining the data is expensive. Also, their distribution in time is usually inadequate for monitoring. The satellite altimeter has opened a new dimension for the monitoring of the variability of sea surface height. The Geosat altimeter gives virtually global coverage at reasonable intervals of time, but its measurements are related to a rather uncertain datum due to the orbit error. Repeat orbits of the altimeter differ from each other by several meters, and in some cases by as much as $15 \mathrm{~m}$ (C. Wunsch and S. Imawaki, personal communication, 1989). The orbit errors are concentrated at long length scales and are often removed by subtracting a linear or quadratic function from each pass of the altimeter. Although this technique is very effective for ocean mesoscale features that have length scales of less than $1000 \mathrm{~km}$, significant errors can remain at longer length scales and lower frequencies and lead to the datum problem. The fact that the altimeter data can be processed to accurately reveal mesoscale variability does not imply that long-term fluctuations will also be properly benchmarked.

In this study we will compare sea surface height data from Geosat altimeter observations with measurements of sea level at island stations in the Pacific. The altimeter observations are from published maps that are produced operationally. We have chosen to use operational products for this comparison because these products are widely distributed, are claimed to be accurate, and are often the only source of information open to most scientists. We realize that the quality of the altimeter data set is improving with time as processing techniques evolve and orbit accuracy improves. Our intention here is not to condemn altimetry products but to use a widely available data set to document a problem that must be solved in the process of improving the sea surface height data sets. 


\section{STATION LOCATIONS}

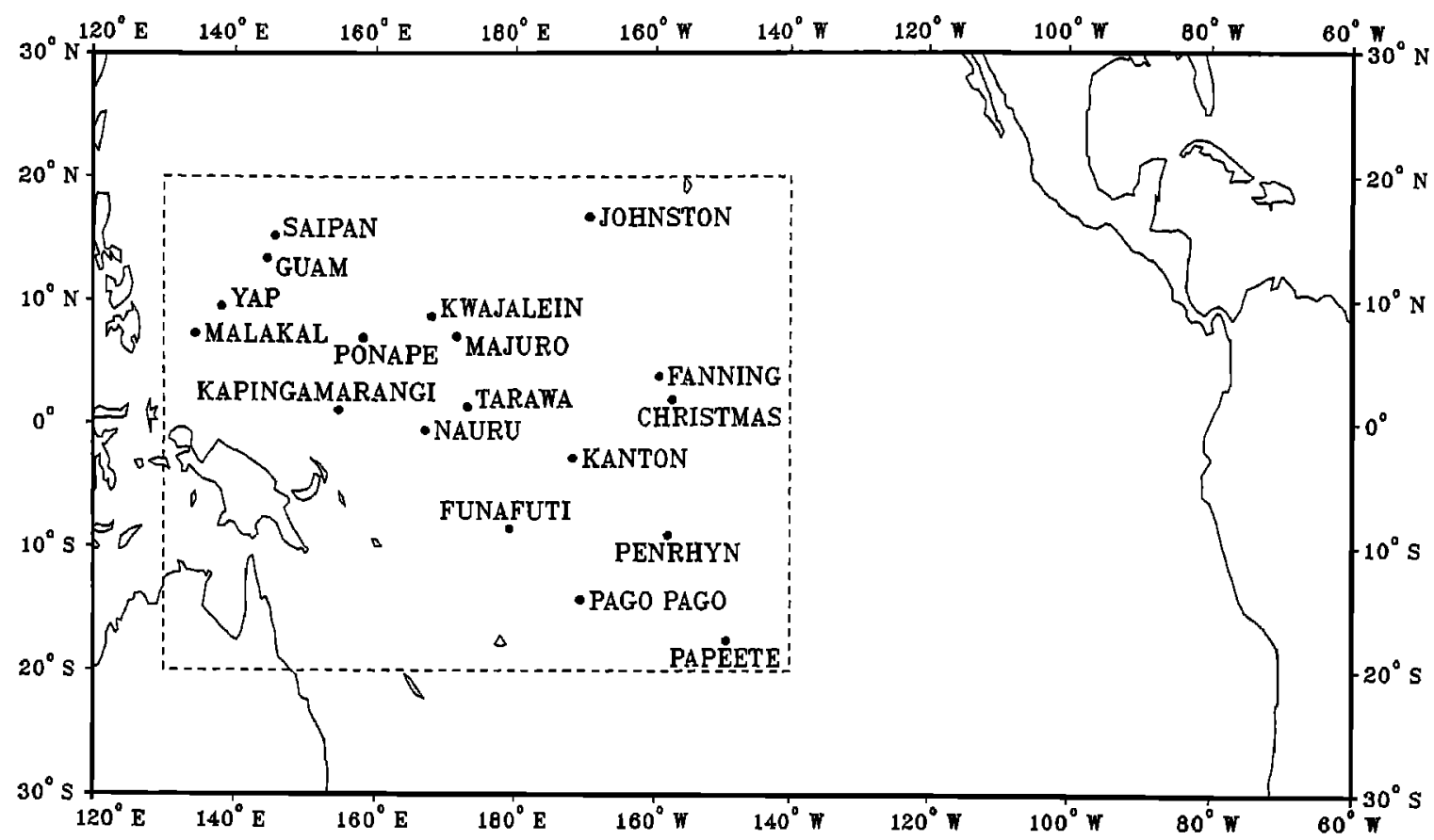

Fig. 1. Location of the sea level stations used for comparison with the altimeter data. Station positions are given in Table 1.

\section{DATA}

Since 1987 the Climate Diagnostics Bulletin of the U.S. National Weather Service has published maps of sea surface height derived from the Geosat altimeter. These maps now

TABLE 1. Station Locations and Statistics of the Comparisons Between the Island Sea Level Data and the Geosat Sea Surface Height Data

\begin{tabular}{|c|c|c|c|c|c|c|}
\hline \multirow[b]{2}{*}{ Station } & \multirow[b]{2}{*}{ Latitude } & \multirow[b]{2}{*}{ Longitude } & \multicolumn{2}{|c|}{$r, \%$} & \multirow[b]{2}{*}{$\sigma^{*}$} & \multirow[b]{2}{*}{$\Delta \dagger$} \\
\hline & & & $\begin{array}{l}\text { This } \\
\text { Study }\end{array}$ & $\begin{array}{c}\text { Tai et al. } \\
\text { [1989] }\end{array}$ & & \\
\hline Kwajalein & $08^{\circ} 44^{\prime} \mathrm{N}$ & $167^{\circ} 44^{\prime} \mathrm{E}$ & 95 & 54 & 2.6 & -11.2 \\
\hline Fanning & $03^{\circ} 52^{\prime} \mathrm{N}$ & $159^{\circ} 22^{\prime} \mathrm{W}$ & 91 & 94 & 4.2 & +7.1 \\
\hline Ponape & $06^{\circ} 59^{\prime} \mathrm{N}$ & $158^{\circ} 14^{\prime} \mathrm{E}$ & 89 & 59 & 4.3 & -14 \\
\hline Majuro & $07^{\circ} 05^{\prime} \mathrm{N}$ & $171^{\circ} 23^{\prime} \mathrm{E}$ & 82 & 51 & 3.6 & -8.3 \\
\hline Christmas & $01^{\circ} 57^{\prime} \mathrm{N}$ & $157^{\circ} 28^{\prime} \mathrm{W}$ & 80 & 78 & 4.5 & +6.3 \\
\hline Nauru & $00^{\circ} 32^{\prime} \mathrm{S}$ & $166^{\circ} 54^{\prime} \mathrm{E}$ & 78 & 19 & 4.7 & -1.4 \\
\hline Tarawa & $01^{\circ} 22^{\prime} \mathrm{N}$ & $172^{\circ} 56^{\prime} \mathrm{E}$ & 74 & 48 & 4.3 & +0.1 \\
\hline Kapingamarangi & $01^{\circ} 06^{\prime} \mathrm{N}$ & $154^{\circ} 47^{\prime} \mathrm{E}$ & 72 & $\cdots$ & 4.3 & -16 \\
\hline Kanton & $02^{\circ} 48^{\prime} \mathrm{S}$ & $171^{\circ} 43^{\prime} \mathrm{W}$ & 69 & 64 & 4.3 & -3.7 \\
\hline Guam & $13^{\circ} 26^{\prime} \mathrm{N}$ & $144^{\circ} 39^{\prime} \mathrm{E}$ & 65 & 59 & 6.6 & -14.0 \\
\hline Penrhyn & $09^{\circ} 01^{\prime} \mathrm{S}$ & $158^{\circ} 04^{\prime} \mathrm{W}$ & 51 & 56 & 4.2 & +3.4 \\
\hline Pago Pago & $14^{\circ} 17^{\prime} \mathrm{S}$ & $170^{\circ} 41^{\prime} \mathrm{W}$ & 43 & 54 & 7.5 & -4 \\
\hline Saipan & $15^{\circ} 14^{\prime} \mathrm{N}$ & $145^{\circ} 44^{\prime} \mathrm{E}$ & 42 & 53 & 8.8 & -1.4 \\
\hline Papeete & $17^{\circ} 32^{\prime} \mathrm{S}$ & $149^{\circ} 34^{\prime} \mathrm{W}$ & 39 & $\ldots$ & 3.7 & +2.2 \\
\hline Funafuti & $08^{\circ} 31^{\prime} \mathrm{S}$ & $179^{\circ} 12^{\prime} \mathrm{E}$ & 38 & 72 & 5.9 & -6.9 \\
\hline Malakal & $07^{\circ} 20^{\prime} \mathrm{N}$ & $134^{\circ} 28^{\prime} \mathrm{E}$ & 26 & 87 & 10.3 & -14.7 \\
\hline Johnston & $16^{\circ} 45^{\prime} \mathrm{N}$ & $169^{\circ} 31^{\prime} \mathrm{W}$ & 21 & 16 & 6.1 & -4.7 \\
\hline Yap & $09^{\circ} 31^{\prime} \mathrm{N}$ & $138^{\circ} 08^{\prime} \mathrm{E}$ & 13 & 85 & 7.7 & -9.8 \\
\hline
\end{tabular}

${ }^{*}$ Root-mean-square differences between the island sea level and Geosat sea surface height data sets during the study period December 1986 to November 1987.

$\uparrow$ Difference in mean sea level during the period December 1986 to November 1987 and the analogous mean Geosat sea surface height. cover the equatorial Pacific Ocean from $20^{\circ} \mathrm{N}$ to $20^{\circ} \mathrm{S}$ and from $135^{\circ} \mathrm{E}$ to $90^{\circ} \mathrm{W}$, and represent conditions on the first day of each month. The procedures for the preparation of these maps have been outlined by Cheney et al. [1989]. The maps are based on time series of sea surface height in areas of $2^{\circ}$ of latitude by $8^{\circ}$ of longitude. The gridded numerical values for each month of the period December 1, 1986, to November 1, 1987, were kindly provided for this analysis by $\mathrm{R}$. Cheney and L. Miller of the National Ocean Service. The values are referred to the mean of a reference period from April 1985 to April 1986.

Sea level at Pacific island stations was measured at the tide gauges of the Pacific sea level network of the Tropical Ocean-Global Atmosphere (TOGA) program [Wyrtki et al., 1988]. The hourly data from the tide gauges were filtered with a convolution-type numerical filter that is 5 days long. This filter is designed to allow a daily subsampling of the hourly data without significant aliasing from the energetic diurnal and semidiurnal tides. These filtered daily values of

TABLE 2. Christmas Island Filtered Daily Sea Level Versus Geosat Sea Surface Height Data

\begin{tabular}{ccc}
\hline$L$, days & $\sigma, \mathrm{cm}$ & $r, \%$ \\
\hline 5 & 5.7 & 69 \\
11 & 5.2 & 76 \\
15 & 4.9 & 79 \\
21 & 4.5 & 80 \\
25 & 4.5 & 79 \\
31 & 4.6 & 77
\end{tabular}

The first column gives the length of the running mean filter used. The second and third columns give the rms differences and the correlation coefficients between the two data sets. 

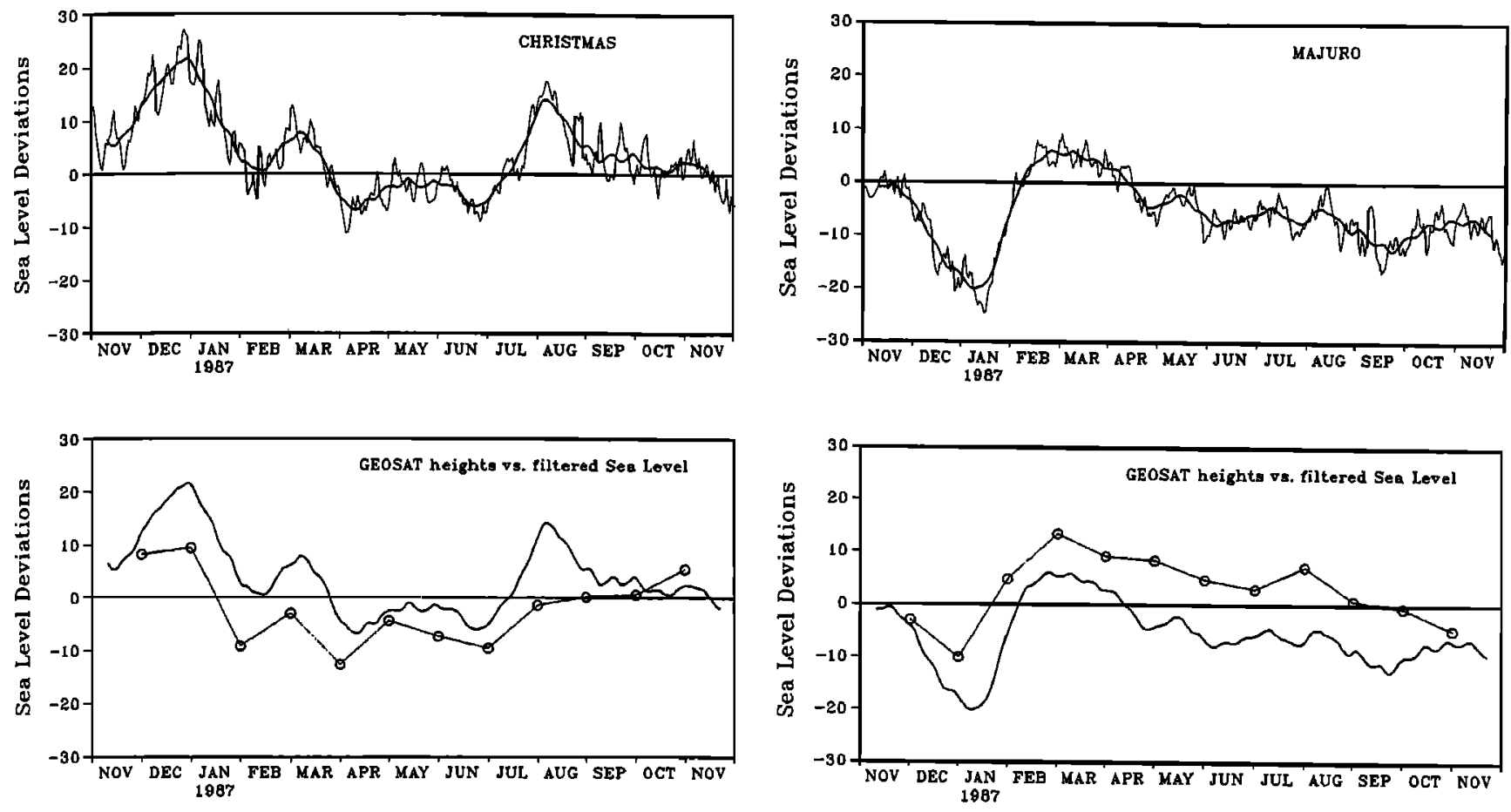

Fig. $2 a$

Fig. $2 b$


Fig. $2 c$

Fig. $2 d$

Fig. 2. (Top) Daily sea level at island sea level stations together with the low-pass-filtered record (21-day filter). (Bottom) Low-pass-filtered record for sea level together with the Geosat altimeter heights. Both records are referred to the April 1985 to April 1986 reference period. (a) Christmas Island. (b) Majuro. (c) Ponape. (d) Kwajalein. (e) Kapingamarangi. ( $f$ ) Saipan. ( $g$ ) Guam. (h) Yap.

sea level are used throughout this study. All sea level data are referred to local benchmarks for datum control. A map of the station locations is shown in Figure 1, and the positions are given in Table 1. For the purpose of this comparison the sea level data have also been referred to the mean sea level during the same reference period (April 1985 to April 1986) that was used for the altimeter data. Thus in both data sets the mean at each point in space computed over April 1985 to 

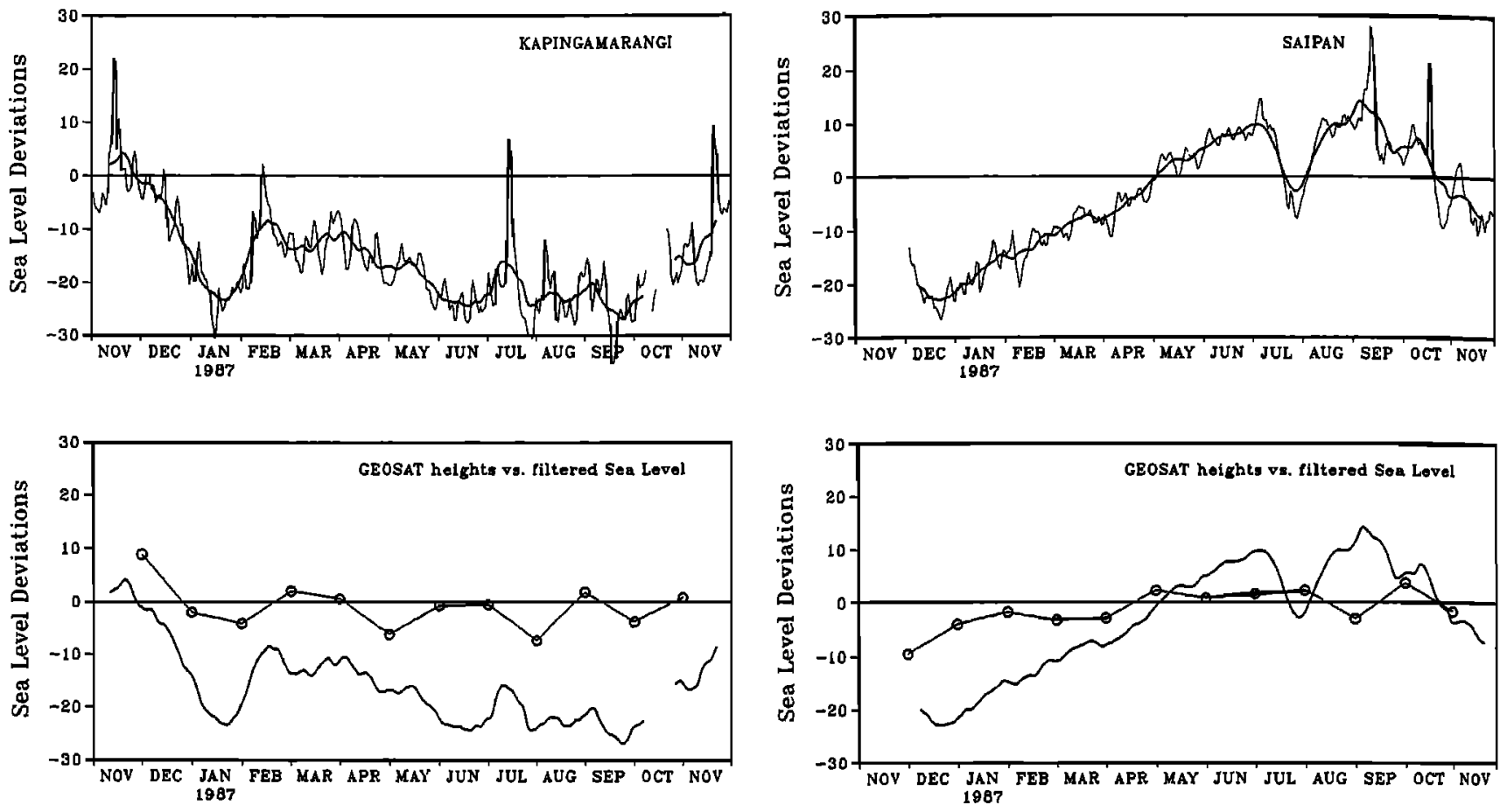

Fig. $2 e$

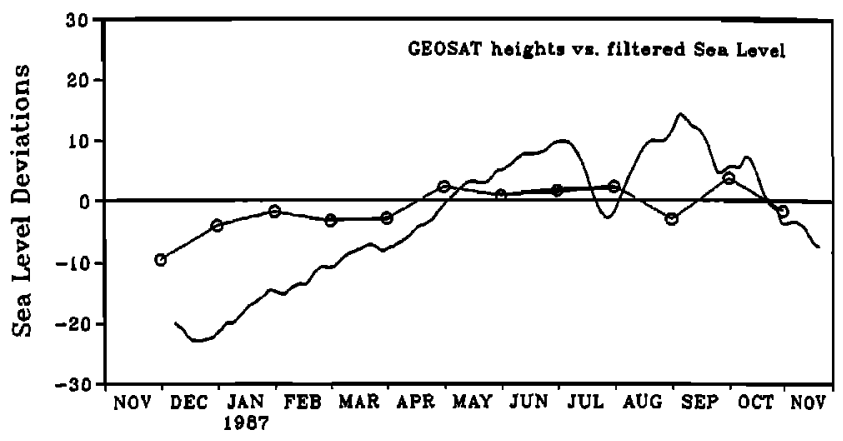

Fig. $2 f$
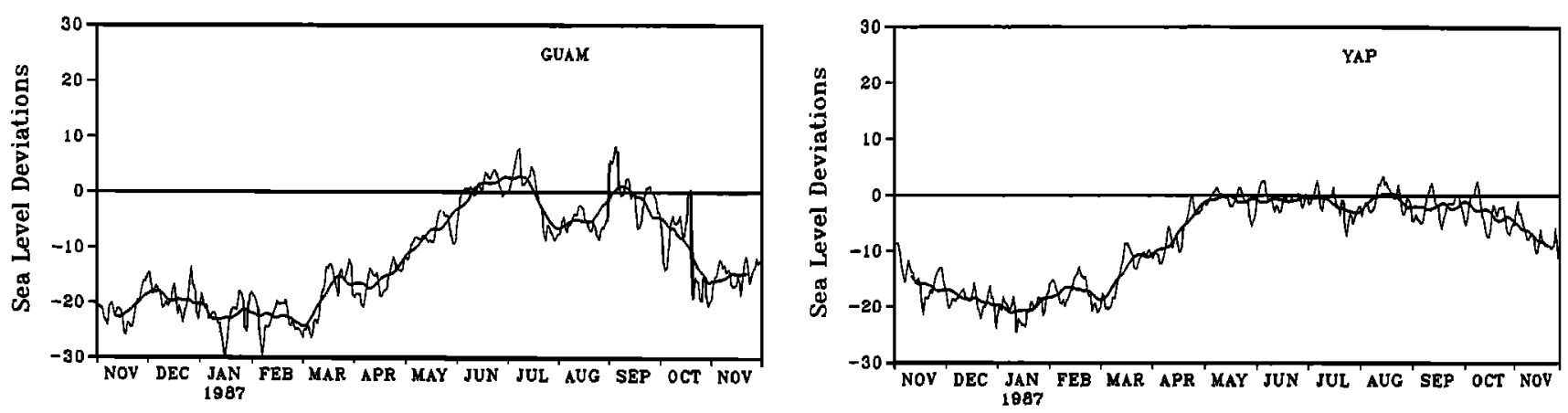



Fig. $2 g$

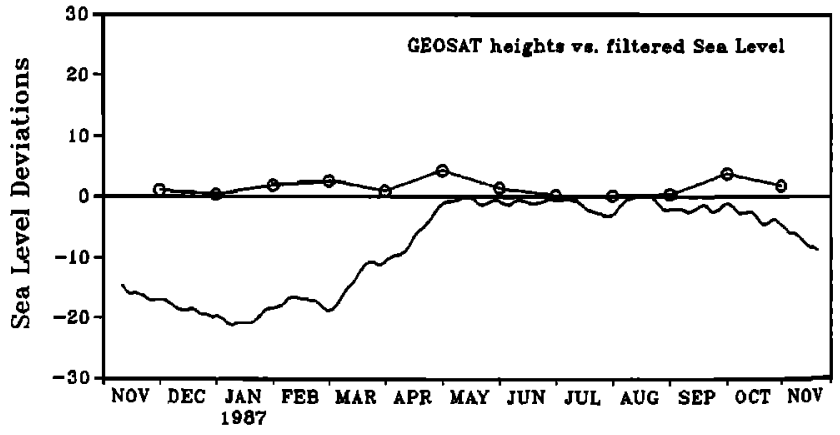

Fig. $2 h$

Fig. 2. (continued)

April 1986 is equal to zero. This ensures that any differences between the two data sets are not due to the use of a different reference surface but are in fact a measure of the stability of the altimeter's "datum."

\section{Comparison of Time Series}

In order for time series of sea level and Geosat sea surface heights to be compared, the data need to be filtered appro- 
Difference of Dec 86 to Nov 87 means

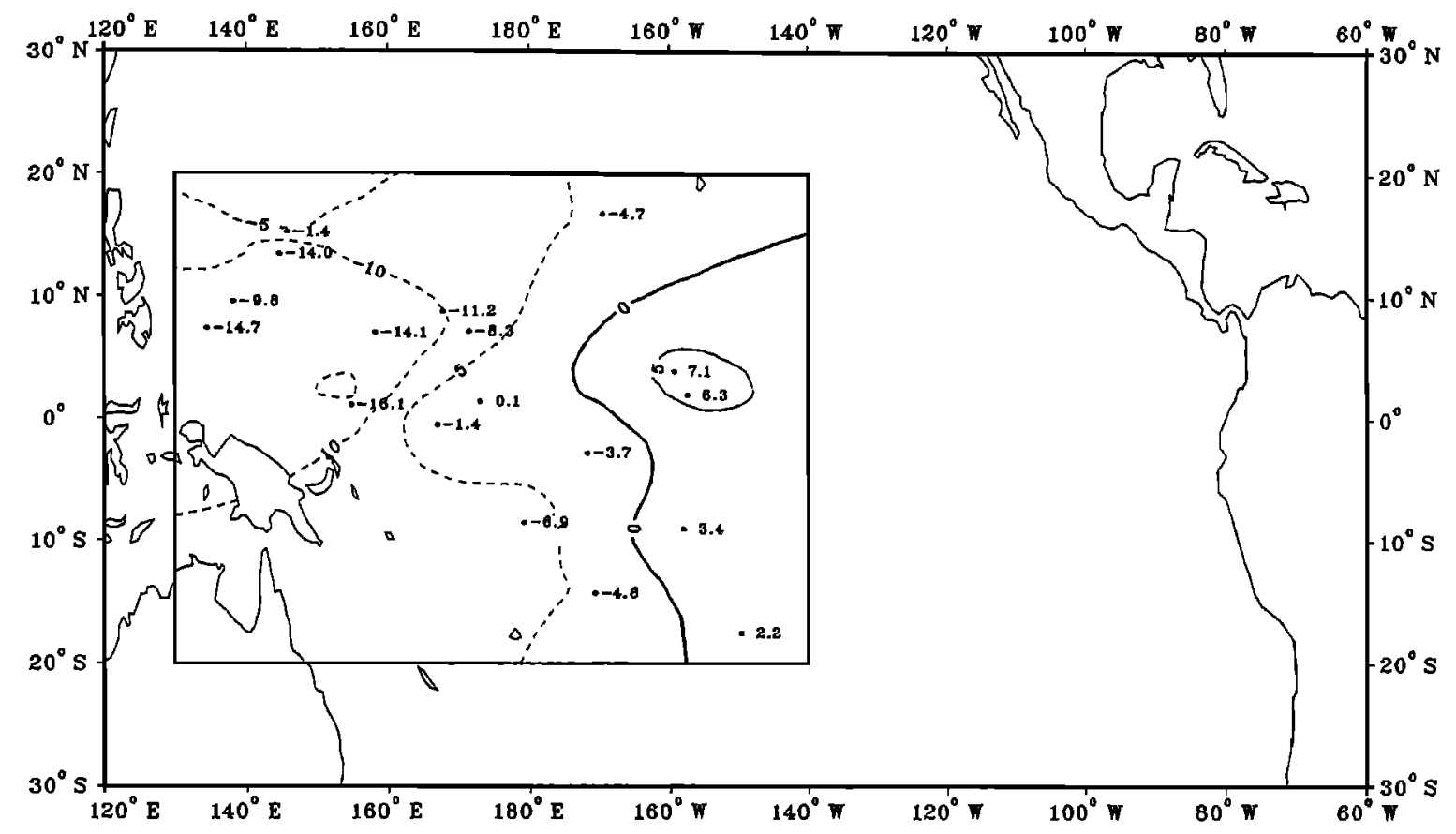

Fig. 3. December 1986 to November 1987 means as computed from the sea level gauges minus the analogous means computed from the Geosat sea surface height data. Both data sets have been referenced to their mean values during the time period April 1985 to April 1986. The units are centimeters.

priately. The daily sea level values can be filtered in any desirable fashion, but the satellite data are observed at somewhat irregular intervals. Data from each orbit crossing the $2^{\circ} \times 8^{\circ}$ area are used to construct a time series of sea surface height for that area or grid point. Such data are available every 1.5 days on the average and are being smoothed by an objective analysis procedure with a 15-day decorrelation time [Cheney et al., 1989].

In order to find the filter length that minimizes the effect of differing filtering procedures on our analysis, we have used filter lengths between 5 and 31 days to calculate the standard deviations and correlations between the two data sets at Christmas Island. The results are given in Table 2 and show that the standard deviation decreases and the correlation increases with filter length. For a filter length of 21 days the standard deviation has a weak minimum and the correlation

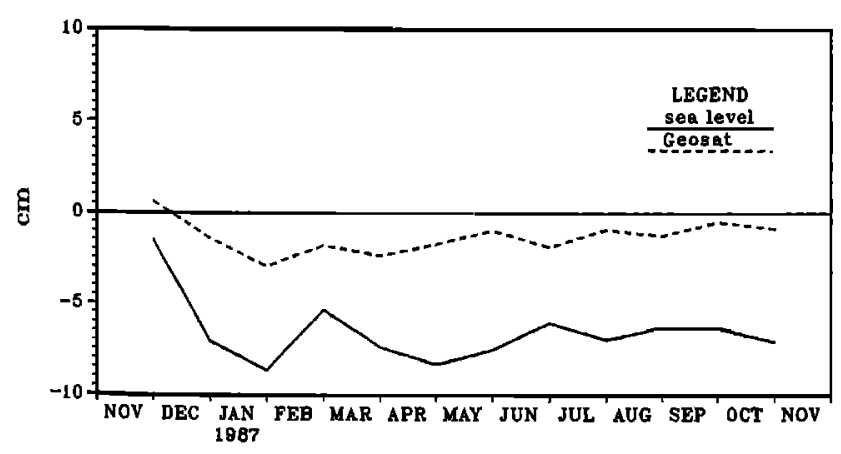

Fig. 4. Temporal evolution of the spatial mean difference between the sea level data and the Geosat sea surface height data. At each point in time, the mean of the 18 sea level stations minus the mean of the 18 corresponding Geosat sea surface height data is plotted. has a weak maximum, and we have consequently chosen a filter of 21 days for the sea level data. We did precisely the same calculations at Majuro and found that 21 days was also an appropriate value at that location.

The record of daily sea level for Christmas Island is shown in Figure $2 a$ together with the record resulting from a 21-day low-pass filtering. Also shown are the sea surface heights derived from Geosat for the first day of each month. These two records show a good agreement, and this comparison has been used by Cheney et al. [1986] and by Miller et al. [1986] to emphasize the quality of the Geosat data.

The altimeter heights are given as deviations from the mean over a reference period from April 1985 to April 1986 at each grid point [Cheney et al., 1989]. Values of sea surface height at the location of each sea level station were obtained through bilinear interpolation of the four surrounding points in the altimeter height grid. A comparison of time series of filtered sea level and interpolated altimeter heights is shown at eight of the stations (Figure 2). Some stations like Kwajalein, Fanning, Majuro, and Christmas show a good correspondence of the records, both in amplitude and phase. They have standard deviations between $2.6 \mathrm{~cm}$ and $4.5 \mathrm{~cm}$ and correlations above 0.8 (Table 1). Similar good correspondence is found at Nauru, Tarawa, and Kanton. They have standard deviations near $4.5 \mathrm{~cm}$ and correlations above 0.7 . It should be noted that most of these stations are along the equator.

At other stations the agreement is considerably less satisfactory. At Ponape (Figure 2c) the altimeter record is almost flat, while the sea level record shows a strong amplitude, resulting in an obvious mismatch in amplitude of the two records despite a high correlation. Also at Kapingamarangi (Figure $2 e$ ) the two records do not match well in amplitude 
Squared correlation coefficient



Fig. 5. Contour plot of the squared correlation values between the sea level data and the Geosat sea surface height data over December 1986 to November 1987. Contour interval is $20 \%$.

despite a reasonably high correlation coefficient. At Saipan (Figure 2f), Guam (Figure $2 g$ ), and Yap (Figure $2 h$ ), and also at Malakal, large changes in sea level are not represented by corresponding altimeter signals. At Yap an $18-\mathrm{cm}$ rise of sea level from February to May is not at all apparent in the altimeter record. At these four stations the altimeter fails to register major events in the sea level record.

At many stations the sea level records and the altimeter heights are offset with respect to each other. This is especially apparent at Kwajalein (Figure $2 d$ ), Ponape (Figure $2 c$ ), Kapingamarangi (Figure $2 e$ ), and Guam (Figure $2 g$ ) and also at Malakal. At these stations the altimeter records show values between 11 and $16 \mathrm{~cm}$ higher than the sea level records when referred to the April 1985 to April 1986 reference period. In contrast, sea level is higher than the altimeter values at Christmas and Fanning by 6 and $7 \mathrm{~cm}$. It should be noted that these discrepancies have developed over an interval of only 19 months.

To expand on this observation, we reiterate that the sea level data as well as the altimeter data have been referred to the period April 1985 to April 1986 for which their respective means were set equal to zero. The comparisons in this paper are made for the period November 1986 to November 1987. During the intervening period, discrepancies between the altimeter and the sea level data have developed, and the mean differences between the two data sets are shown in Figure 3 and listed in Table 1. They range from -16 to $+7 \mathrm{~cm}$ and show a very systematic distribution. All positive values are found to the east of $160^{\circ} \mathrm{W}$. Largest negative values are in the far western equatorial Pacific between Guam and New Guinea. We have also computed the means of the altimeter and the sea level data of the 18 stations for each month (Figure 4). This figure shows an increasing discrepancy during the comparison period. The altimeter means only partially follow the drop in sea level from November 1986 to February 1987, and they remain about $7 \mathrm{~cm}$ higher during the remainder of 1987.

Several previous comparisons of Geosat sea surface heights and sea level data have used correlations and rootmean-square differences over a specified study period to quantify the agreement. Because such calculations begin by removing the mean difference between the two data sets, they do not address problems such as we have described above. Moreover, even these calculations do not suggest that the differences between the two data sets are randomly distributed. Figure 5 shows a map of the square of the correlation coefficient that reveals a clear spatial pattern. Largest values are between the equator and $10^{\circ} \mathrm{N}$, where fluctuations of sea level and altimeter height are highly correlated. The lowest values are at the periphery of the map, at Johnston Island, at the Palau Islands near the Southeast Asian monsoon region, and under the Southwest Pacific Convergence Zone. We note that the low correlations in the latter two areas correspond to regions where the annual variation of the water vapor content is large.

Another comparison between sea level and altimeter heights in the equatorial Pacific has been made by Tai et al. [1989] using data from the classified portion of the Geosat mission from May 1985 to August 1986. The correlation coefficients determined by them are shown in the last column of Table 1. Correlations at five stations were much better during our (later) period, at five stations they were much better during the earlier period, and at six stations, were not substantially different. Two stations had no data during the earlier period. These numbers are expected if the pattern of correlation has changed in a random manner between the two time periods. This randomness raises serious questions about the use of the sea surface height data from the 
altimeter to study variability on time scales longer than a year. This is because high correlations in a given area in one year do not insure that the sea surface height observations in the same area at another time will also be reliable. Unless the reasons for these interannual variations are determined and corrected, it will be necessary to continuously check the sea surface height data against the sea level data. Essentially, the tide gauges will have to be used as benchmarks for the altimeter data.

In conclusion, the comparisons presented here show that the particular altimeter-observed sea surface variability that we have examined is not accurate on time scales longer than a year. This fact will make it almost impossible to determine trends of the order of a few centimeters over 1 year, and one must view these altimeter heights as being referred to an uncertain datum that varies in time. Of course, the observations of mesoscale variability over time intervals from weeks to a year are not as sensitive to the datum uncertainty. However, the datum uncertainty will negatively impact efforts to use the altimeter data for monitoring large-scale, low-frequency variability. Improvements in the processing techniques and in the orbit calculations should reduce these errors. To make altimeter data useful for the monitoring of interannual sea level changes, and to provide the necessary datum, it may become necessary to refer them to in situ sea level observations. Techniques for such a complementary use of the two data sets will need to be worked out.

Acknowledgments. We thank Robert Cheney and Laury Miller for making a year of their operational Geosat maps of the Pacific available to us in digital form. Shikiko Nakahara provided valuable computing assistance. Support for this study was provided by the National Science Foundation under grant OCE8515404; by the TOGA Sea Level Center through NOAA Cooperative Agreement NA85ABH00032 to the Joint Institute for Marine and Atmospheric Research (JIMAR), University of Hawaii; and by NASA through the Jet Propulsion Laboratory as part of the TOPEX Altimetry Research in Ocean Circulation Mission. Hawaii Institute of Geophysics contribution 2219; JIMAR contribution 89-0208.

\section{REFERENCES}

Cheney, R., B. Douglas, R. Agreen, L. Miller, D. Milbert, and D. Porter, The Geosat altimeter mission: A milestone in satellite oceanography, Eos Trans. AGU, 67, 1354-1355, 1986.

Cheney, R., B. Douglas, and L. Miller, Evaluation of Geosat altimeter data with application to tropical Pacific sea level variability, J. Geophys. Res., 94, 4737-4748, 1989.

Miller, L., R. Cheney, and D. Milbert, Sea level time series in the equatorial Pacific from satellite altimetry, Geophys. Res. Lett., $13,475-478,1986$.

Tai, C.-K., W. White, and S. Pazan, Geosat crossover analysis in the tropical Pacific, 2, Verification analysis of altimetric sea level maps with expendable bathythermograph and island sea level data, J. Geophys. Res., 94, 897-908, 1989.

Wyrtki, K., K. Constantine, B. Kilonsky, G. Mitchum, B. Miyamoto, T. Murphy, and S. Nakahara, The Pacific Island Sea Level Network, JIMAR Data Rep. 002, 71 pp., Univ. of Hawaii, Honolulu, 1988.

G. Mitchum and K. Wyrtki, TOGA Sea Level Center, University of Hawaii, 1000 Pope Road, Honolulu, HI 96822.

(Received May 30, 1989;

revised August 22, 1989;

accepted August 22, 1989.) 